\title{
Electron impact ionisation cross sections of iron oxides ${ }^{\star}$
}

\author{
Stefan E. Huber ${ }^{1,2, a}$, Andreas Mauracher ${ }^{1}$, Ivan Sukuba ${ }^{1,3}$, Jan Urban $^{3}$, Thana Maihom ${ }^{4}$, \\ and Michael Probst ${ }^{1}$ \\ ${ }^{1}$ Institute of Ion Physics and Applied Physics, University of Innsbruck, Technikerstraße 25, 6020 Innsbruck, Austria \\ ${ }^{2}$ Institute for Basic Sciences in Engineering Science, University of Innsbruck, Technikerstraße 13, 6020 Innsbruck, \\ Austria \\ 3 Department of Nuclear Physics and Biophysics, Faculty of Mathematics, Physics and Informatics, Comenius \\ University in Bratislava, 84248 Bratislava, Slovakia \\ ${ }^{4}$ Vidyasirimedhi Institute of Science and Technology, School of Energy Science and Engineering, 555 Moo 1 \\ Payupnai, Wangchan, Rayong 21210, Thailand
}

Received 6 May 2017 / Received in final form 26 September 2017

Published online 19 December 2017

(C) The Author(s) 2017. This article is published with open access at Springerlink.com

\begin{abstract}
We report electron impact ionisation cross sections (EICSs) of iron oxide molecules, $\mathrm{Fe}_{x} \mathrm{O}_{x}$ and $\mathrm{Fe}_{x} \mathrm{O}_{x+1}$ with $x=1,2,3$, from the ionisation threshold to $10 \mathrm{keV}$, obtained with the Deutsch-Märk (DM) and binary-encounter-Bethe (BEB) methods. The maxima of the EICSs range from 3.10 to $9.96 \times 10^{-16} \mathrm{~cm}^{2}$ located at $59-72 \mathrm{eV}$ and 5.06 to $14.32 \times 10^{-16} \mathrm{~cm}^{2}$ located at $85-108 \mathrm{eV}$ for the DM and BEB approaches, respectively. The orbital and kinetic energies required for the BEB method are obtained by employing effective core potentials for the inner core electrons in the quantum chemical calculations. The BEB cross sections are 1.4-1.7 times larger than the DM cross sections which can be related to the decreasing population of the Fe 4 s orbitals upon addition of oxygen atoms, together with the different methodological foundations of the two methods. Both the DM and BEB cross sections can be fitted excellently to a simple analytical expression used in modelling and simulation codes employed in the framework of nuclear fusion research.
\end{abstract}

\section{Introduction}

Plasma-wall interaction (PWI) is regarded as one of the key issues in nuclear fusion research. In nuclear fusion devices, such as the JET or the ITER tokamak (presently under construction), first-wall materials are those parts of the devices that will be directly exposed to plasma components. In ITER, the first-wall is envisaged to be coated with beryllium and tungsten [1]. After ITER, in the fusion program DEMO and beyond it in industrial applications of nuclear fusion, it seems likely that the highly toxic and hence difficult to handle beryllium will be avoided. The use of special stainless steels (i.e. the Eurofer steel envisaged for DEMO $[2,3]$ ) for some portions of the main wall may then come into consideration. Erosion of first-wall materials is an inevitable consequence of the impact of hydrogen and its isotopes as main constituents of the hot plasma $[4,5]$. Besides the formation of gas-phase atomic species in various charge states, also molecular species are expected to be formed via PWI processes. Disturbance of the fusion plasma and unfavourable re-deposition of materials and composites

\footnotetext{
* Supplementary material in the form of one pdf file available from the Journal web page at

https://doi.org/10.1140/epjd/e2017-80308-2.

${ }^{a}$ e-mail: s.huber@uibk.ac.at
}

in other areas of the vessel are expected to be some of the undesired consequences [6-9]. Hence, detailed knowledge and quantification of interactions between atoms, molecules and the plasma as well as of the transport of impurities is of considerable interest for modelling and simulation of fusion plasmas [10]. Collisions of atoms and molecules with plasma electrons are one important class of such processes. They are mainly characterised by the respective electron-impact ionisation cross sections (EICSs) and their knowledge is especially important for modelling the plasma energy balance. Apart from magnetic confinement fusion, EICS data also are quite valuable due to the role of electron-induced reactions in astrophysics and in a variety of other applications such as low-temperature processing plasmas, gas discharges, and in chemical analysis [11].

During the past few decades, a number of semiempirical methods that typically use electronic structure information from quantum chemical calculations as input have been developed in order to derive absolute EICSs for various molecules. Their accuracy is usually in the same range as the one of experimental data. Among those, the most-widely used methods are the binary-encounterBethe (BEB) theory of Kim et al. [12,13] and the DeutschMärk (DM) formalism [14]. These methods have been successfully applied to atoms, molecules, clusters, ions and radicals [15]. 
Concerning fusion-relevant species, EICSs were reported earlier for beryllium [16,17], its hydrides [18], tungsten and its oxides [19,20], beryllium-tungsten clusters [21] and iron hydrides were also been covered recently [22]. In this work we report calculated EICSs using both the BEB and the DM methods for neutral iron oxide molecules, in particular for $\mathrm{Fe}_{x} \mathrm{O}_{x}$ and $\mathrm{Fe}_{x} \mathrm{O}_{x+1}$ compounds with $x=1,2,3$. Small amounts of oxygen are inevitably present in fusion plasma as are elements of similar atomic weight like nitrogen and argon. Moreover, such oxygen atoms will interact with surface iron or with sputtered iron atoms since the formation of iron oxide is highly exothermic. Electron impact cross sections and EICSs for some of the considered molecules ( $\mathrm{FeO}, \mathrm{Fe}_{2} \mathrm{O}_{3}$ and $\mathrm{Fe}_{3} \mathrm{O}_{4}$ ) were estimated earlier [23] by applying the additivity rule, i.e. by simply summing the respective cross sections of the atoms constituting a molecule. This can be seen as an upper limit for the EICSs calculated by us which will be discussed further in Section 3.2. Photoionisation studies [24,25] suggest that the most prevalent neutral iron oxide clusters in the gas-phase are of the form $\mathrm{Fe}_{x} \mathrm{O}_{x}, \mathrm{Fe}_{x} \mathrm{O}_{x+1}$ and $\mathrm{Fe}_{x} \mathrm{O}_{x+2}$ with the more oxygen rich clusters being favoured for larger values of $x$. Especially for small values of $x<10$, the most abundant iron clusters are suggested to be of the stoichiometry $\mathrm{Fe}_{x} \mathrm{O}_{x}$ and $\mathrm{Fe}_{x} \mathrm{O}_{x+1}$ which is why we are focusing on these clusters in the present work. Moreover, collision induced dissociation studies of small iron oxide cluster cations [26] revealed that predominant decomposition pathways are related to the loss of neutral $\mathrm{O}_{2}$ and of $\mathrm{FeO}, \mathrm{FeO}_{2}, \mathrm{Fe}_{2} \mathrm{O}_{2}$ and $\mathrm{Fe}_{2} \mathrm{O}_{3}$ fragments which makes the latter especially interesting to study in the framework of PWI processes. Due to the unique properties of iron oxide nanoparticles and their applications [27-30], iron oxide clusters, as their building blocks, were subject to numerous theoretical studies focusing on energetic, geometrical and magnetic properties, see e.g. references [31-37]. While the structures reported by Jones et al. [32] were used by us as input for structural optimisation (Sect. 2.3), the mentioned studies allowed us also to cross-validate our results for the obtained structural parameters and the energetics (Sect. 3.1). Except for the study reporting electron impact cross sections obtained by applying the additivity rule [23] mentioned above, neither theoretical nor experimental EICSs for iron oxide clusters were published to the best of our knowledge.

In addition to the EICSs, we also report parameters obtained by fitting the calculated cross sections to an expression commonly used in codes modelling the impurity transport in fusion edge plasmas such as ERO [38-40].

\section{Methods}

\subsection{The DM formalism}

The DM formalism was originally developed as an easy-touse semi-empirical approach for the calculation of EICSs of atoms in their electronic ground state from threshold to about $100 \mathrm{eV}$ [14]. In its most recent variant [15,41], the total single EICS $\sigma$ of an atom is expressed as:

$$
\sigma_{\mathrm{DM}}(u)=\sum_{n, l} g_{n l} \pi r_{n l}^{2} \xi_{n l} b_{n l}^{(q)}(u)\left[\ln \left(c_{n l} u\right) / u\right]
$$

where $r_{n l}$ is the radius of maximum radial density of the atomic sub-shell characterised by quantum numbers $n$ and $l$ (as listed in column 1 in the tables of Desclaux [42]) and $\xi_{n l}$ is the number of electrons in that sub-shell. The sum extends over all atomic sub-shells labelled by $n$ and $l$. The $g_{n l}$ are weighting factors, which were originally determined by a fitting procedure [43,44] using reliable experimental cross section data for a few selected atoms, for which the accuracy of the reported rate is in the range of $7-15 \%$. The reduced energy $u$ is given by $u=E / E_{n l}$, where $E$ refers to the incident energy of the electrons and $E_{n l}$ denotes the ionisation energy of the sub-shell characterised by $n$ and $l$. The energy-dependent quantities $b_{n l}^{(q)}(u)$ were introduced in an effort to merge the highenergy region of the ionisation cross section, which follows the Born-Bethe approximation [45], with the DM formula of the cross sections in the regime of low impact energies. The function $b_{n l}^{(q)}$ in equation (1) has the explicit form:

$$
b_{n l}^{(q)}=\frac{A_{1}-A_{2}}{1+\left(u / A_{3}\right)^{p}}+A_{2} .
$$

The four constants $A_{1}, A_{2}, A_{3}$ and $p$ were determined, together with $c_{n l}$, from reliably measured cross sections for the various values of $n$ and $l$. The superscript $q$ refers to the number of electrons in the $(n, l)$-th sub-shell and allows the possibility to use slightly different functions $b_{n l}^{(q)}$ depending on the number of electrons in the respective sub-shell. At high impact energies $u$ goes to infinity, the first term in equation (2) goes to zero and $b_{n l}^{(q)}(u)$ becomes a constant ensuring the high-energy dependence of the cross sections predicted by the Born-Bethe theory $[45,46]$.

The DM formalism has been extended to the calculation of EICSs of atoms in excited states, molecules and free radicals, atomic and molecular ions, and clusters [15]. For the calculation of the EICS of a molecule, a population analysis $[47,48]$ must be carried out to obtain the weights with which the atomic orbitals of the constituent atoms contribute to each occupied molecular orbital. These weights are obtained from the coefficients of the occupied molecular orbital after a transformation employing the overlap matrix in order to correct for the non-orthogonality of the atomic basis functions.

\subsection{The BEB method}

The BEB model [13] was derived from the binaryencounter-dipole model [12] by replacing the $d f / d E$ term for the continuum dipole oscillator strengths by a simpler form. Thus, a modified form of the Mott cross section together with the asymptotic form of the Bethe theory describing the electron-impact ionisation of an atom was combined into an expression for the cross section of each 
molecular orbital:

$$
\sigma(t)=\frac{S}{t+u+1}\left[\frac{\ln (t)}{2}\left(1-\frac{1}{t^{2}}\right)+1-\frac{1}{t}-\frac{\ln (t)}{t+1}\right]
$$

where $t=T / B, u=U / B, S=4 \pi a_{0}^{2} N R^{2} / B^{2}, a_{0}$ denotes the Bohr radius (0.5292 $\AA$ ), $R$ is the Rydberg energy $(13.6057 \mathrm{eV})$, and $T$ denotes the incident electron energy. $N, B$ and $U$ are the electron occupation number, the binding energy (ionisation energy), and the average kinetic energy of the respective molecular orbital, respectively. In the BEB model, the total cross section, similarly to the DM method, is then obtained by summation over the cross sections for all molecular orbitals.

The quantum chemical data needed to calculate EICSs are normally derived from all-electron calculations. For heavy elements and molecules containing them valence-shell-only calculations using effective-core potentials (ECPs) [49] can be used. This facilitates the quantum chemical calculations and allows the incorporation of relativistic effects. Due to the lack of inner radial nodes of the pseudo-valence orbitals, their kinetic energies are lower than normal and equation (3) can be used to determine the BEB cross section [50] avoiding the requirement of introducing an additional modification in equation (3) which became known as "acceleration correction" [51]. This combination of methods has earlier been recommended over using all-electron calculations for molecules that contain heavy atoms (with atomic number $Z>10$ ) [52]. In an earlier work on iron hydrogen clusters, we also compared BEB cross sections obtained from all-electron calculations and by employing ECPs. There as well, a better agreement of the latter with the DM cross sections was found [22].

\subsection{Quantum chemical calculations}

We used the structures obtained by Jones et al. [32] for $\mathrm{Fe}_{x} \mathrm{O}_{x}$ and $\mathrm{Fe}_{x} \mathrm{O}_{x+1}$ compounds with $x=1,2,3$ as starting geometries that were further optimised employing the B3LYP [53] density functional in conjunction with the Def2-TZVP basis set $[54,55]$. The binding energies, $\mathrm{E}_{\mathrm{BE}}$, of the iron oxide clusters were determined according to:

$$
E_{\mathrm{BE}}\left(\mathrm{Fe}_{x} \mathrm{O}_{y}\right)=x E(\mathrm{Fe})+y E\left(\mathrm{O}_{2}\right) / 2-E\left(\mathrm{Fe}_{x} \mathrm{O}_{y}\right),
$$

where $E(A)$ denotes the energy of compound $A$ including the zero-point vibrational energy.

Occupation, binding energy and average kinetic energy for each molecular orbital as required for the calculation of the BEB cross sections (see Sect. 2.2) were calculated at the HF/CEP-4G level of theory using the geometries obtained with B3LYP/Def2-TZVP. The orbital populations required for the DM formalism were derived from HF calculations in conjunction with the minimal CEP$4 \mathrm{G}$ basis set [56-58]. Orbital energies for the outermost valence electrons were calculated with the OVGF method and the Def2-TZVP basis set [59].

All calculations were performed with the Gaussian 09 software [60].

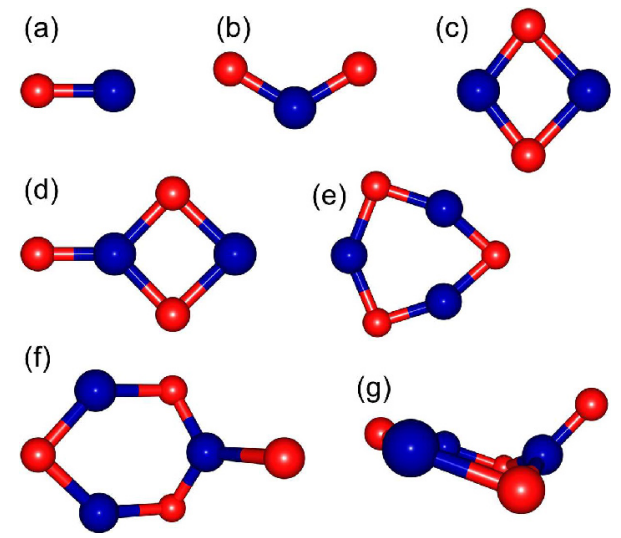

Fig. 1. Optimised geometries of (a) $\mathrm{FeO}(2 S+1=5)$, (b) $\mathrm{FeO}_{2}$ $(2 S+1=5)$, (c) $\mathrm{Fe}_{2} \mathrm{O}_{2}(2 S+1=9)$, (d) $\mathrm{Fe}_{2} \mathrm{O}_{3}(2 S+1=9)$, (e) $\mathrm{Fe}_{3} \mathrm{O}_{3}(2 S+1=3)$, (f) $\mathrm{Fe}_{3} \mathrm{O}_{4}(2 S+1=11$; top view) and (g) $\mathrm{Fe}_{3} \mathrm{O}_{4}(2 S+1=11$; side view). The structures (a)-(e) are planar.

\subsection{Analytical expression of the EICSs}

We fitted the cross sections to an expression that resembles the one used in the ERO code [38-40] which is used for impurity transport simulations in fusion edge plasmas. The fitting expression is given by:

$$
\begin{aligned}
\sigma(E)= & \left(\frac{a_{1}}{E}\right)\left[1-\frac{E_{t}}{E}\right]^{a_{2}} \\
& \times\left[\ln \left(\frac{E}{E_{t}}\right)+a_{3}+a_{4}\left(\frac{E_{t}}{E}\right)\right] .
\end{aligned}
$$

Here the cross section $\sigma$ is expressed in $10^{-16} \mathrm{~cm}^{2}$, the incident electron energy $E$ and the threshold energy (first ionisation energy) $E_{t}$ are both expressed in $\mathrm{eV}$, and the fit parameter $a_{1}$ is expressed in $10^{-16} \mathrm{~cm}^{2} \mathrm{eV}$. The fit parameters $a_{2}, a_{3}$ and $a_{4}$ are dimensionless.

\section{Results}

\subsection{Structures and energetics}

The structures obtained for the considered iron oxide molecules are shown in Figure 1. They correspond to the spin configurations for which the lowest energy was obtained, i.e. the multiplicities $2 S+1=5,5,9,9,3$ and 11 for $\mathrm{FeO}, \mathrm{FeO}_{2}, \mathrm{Fe}_{2} \mathrm{O}_{2}, \mathrm{Fe}_{2} \mathrm{O}_{3}, \mathrm{Fe}_{3} \mathrm{O}_{3}$ and $\mathrm{Fe}_{3} \mathrm{O}_{4}$, respectively. Several spin configurations yielding a multiplicity $2 S+1$ lower and higher than the indicated ones were used during optimisation, but we restrict our following analyses to the obtained lowest energy configurations. The relative energies of the several spin configurations tested are supplied in the supporting information accompanying this article and provided online. It is known that the relative energies of spin configurations and even their order are rather sensitive to the employed method [61], hence we refrain from discussing them further here. Note that all structures up to $\mathrm{Fe}_{3} \mathrm{O}_{3}$ yield (nearly) planar geometries. The complete set of structural parameters 
Table 1. Binding energies, atomisation energies and incremental oxygen binding energies in $\mathrm{Fe}_{x} \mathrm{O}_{x+1}$ (compared to $\mathrm{Fe}_{x} \mathrm{O}_{x}$ ) of the iron oxide molecules considered in this work. The atomisation energies and binding energies of additional oxygen atoms determined by Jones et al. [32] are given in parenthesis for comparison.

\begin{tabular}{lllll}
\hline Molecule & $2 S+1$ & Binding energy $(\mathrm{eV})$ & Atomisation energy $(\mathrm{eV})$ & Binding energy of additional O $(\mathrm{eV})$ \\
\hline $\mathrm{FeO}$ & 5 & 2.11 & $4.75(5.53)$ & - \\
$\mathrm{FeO}_{2}$ & 5 & 3.26 & $8.53(10.53)$ & $3.78(5.00)$ \\
$\mathrm{Fe}_{2} \mathrm{O}_{2}$ & 9 & 6.99 & $12.25(14.46)$ & - \\
$\mathrm{Fe}_{2} \mathrm{O}_{3}$ & 9 & 8.82 & $16.72(19.62)$ & $4.47(5.16)$ \\
$\mathrm{Fe}_{3} \mathrm{O}_{3}$ & 3 & 11.07 & $18.97(24.61)$ & - \\
$\mathrm{Fe}_{3} \mathrm{O}_{4}$ & 11 & 14.90 & $25.43(28.23)$ & $6.46(4.62)$ \\
\hline
\end{tabular}

Table 2. Maxima of the obtained $\mathrm{DM}$ and $\mathrm{BEB}$ cross sections, $\sigma_{\max }$, and their locations, $E_{\max }$, with respect to electron impact energy as well as the ionisation energies, IE, of the iron oxide molecules.

\begin{tabular}{llllll}
\hline Molecule & \multirow{2}{*}{$\mathrm{IE}(\mathrm{eV})$} & \multicolumn{3}{c}{$\mathrm{DM}$} & \multicolumn{2}{c}{$\mathrm{BEB}$} \\
\cline { 3 - 6 } & & $\sigma_{\max }\left(10^{-16} \mathrm{~cm}^{2}\right)$ & $E_{\max }(\mathrm{eV})$ & $\sigma_{\max }\left(10^{-16} \mathrm{~cm}^{2}\right)$ & $E_{\max }(\mathrm{eV})$ \\
\hline $\mathrm{FeO}$ & 8.53 & 3.10 & 59 & 5.06 & 85 \\
$\mathrm{FeO}_{2}$ & 8.88 & 3.95 & 72 & 5.96 & 96.5 \\
$\mathrm{Fe}_{2} \mathrm{O}_{2}$ & 6.21 & 5.95 & 62 & 9.98 & 85.5 \\
$\mathrm{Fe}_{2} \mathrm{O}_{3}$ & 10.29 & 7.16 & 65 & 10.45 & 104 \\
$\mathrm{Fe}_{3} \mathrm{O}_{3}$ & 8.45 & 8.79 & 62 & 12.85 & 108 \\
$\mathrm{Fe}_{3} \mathrm{O}_{4}$ & 11.66 & 9.96 & 65 & 14.32 & 108 \\
\hline
\end{tabular}

such as bond lengths and bond angles is given in the supporting material provided online and some of them are discussed in the following. For the $\mathrm{FeO}$ molecule, we obtain a bond length of $1.608 \AA$ in good agreement with the experimental value of $1.616 \AA[62]$ and earlier theoretical investigations yielding 1.609-1.643 $\AA$ [34], $1.61 \AA$ [32], $1.63 \AA[31], 1.60-1.63 \AA$ [37]. For $\mathrm{FeO}_{2}$ we obtain a bond length of $1.603 \AA$ and a bond angle of $118.3^{\circ}$. Whereas the former yields again good agreement with earlier theoretically obtained values, i.e. $1.62 \AA[32]$ and $1.60 \AA$ [61], in reference [61] a significantly larger bond angle of $138.1^{\circ}$ has been reported. However, the latter was obtained for a spin-triplet configuration employing GGA exchange and correlation functionals which may give rise to this discrepancy since bond angles are usually also more sensitive to the used methodology than bond lengths. The $C 2 v$ symmetry of the obtained $\mathrm{FeO}_{2}$ ground state is, however, in accordance with the literature $[31,32,61]$. Concerning the $\mathrm{Fe}_{2} \mathrm{O}_{2}$ molecule we get a regular tetragonal structure with one $\mathrm{Fe}-\mathrm{O}$ bond length of $1.85 \AA$. Earlier investigations yield also such regular configurations with slightly smaller $\mathrm{Fe}-\mathrm{O}$ bond lengths of $1.81 \AA[32]$ and $1.79 \AA$ [37]. Whereas Ju et al. [37] obtained a spin-septet ground state, the lowest energy spin configuration obtained by Jones et al. [32] was a spin-singlet and in our case the ground state corresponds to $2 S+1=9$. This is another indication of how sensitive the interplay is between the chosen method and the spin configuration. For the larger molecules we note again good agreement in terms of bond lengths compared to the results of reference [32] as well as concerning the planarity of the obtained ground state structures up to $\mathrm{Fe}_{3} \mathrm{O}_{4}[32,36,37]$.

The binding energies determined using equation (4) and the atomisation energies for the considered ground state molecules are given in Table 1 . Both include the zero-point energy correction. We include also the atomisation energies obtained by Jones et al. [32] in Table 1 for comparison. It can be noted that the trend of increasing atomisation energy over the range of considered molecules from the smallest to the largest is conserved. The incremental binding energies of additional oxygen atoms, i.e. the energy difference between $\mathrm{Fe}_{x} \mathrm{O}_{x+1}$ and $\mathrm{Fe}_{x} \mathrm{O}_{x}$, are also included in Table 1.

\subsection{Electron impact ionisation cross sections}

In Table 2, we provide the maxima of the calculated cross sections and their locations with respect to electron impact energy as well as the ionisation energies. The parameters obtained by fitting equation (5) to the respective cross sections are supplied in Table 3. In the supporting information, tabulated data for the DM and BEB cross sections are also included. Figure 2 shows the various cross sections and fitted functions.

The ionisation energy obtained for $\mathrm{FeO}(8.53 \mathrm{eV})$ is in excellent agreement with the experimental value of $8.56 \mathrm{eV}$ [63]. Also the ionisation energy obtained for $\mathrm{FeO}_{2}$ $(8.88 \mathrm{eV})$ is in fair agreement with the experimental one, i.e. $9.5 \pm 0.5 \mathrm{eV}[64]$.

The maxima of the obtained EICSs range from 3.10 to $9.96 \times 10^{-16} \mathrm{~cm}^{2}$ located at $59-72 \mathrm{eV}$ and 5.06 to $14.32 \times 10^{-16} \mathrm{~cm}^{2}$ located at $85-108 \mathrm{eV}$ for DM and BEB, respectively, increasing smoothly for increasing size of the considered molecules. We note that for both, DM and $\mathrm{BEB}$, the magnitude of the cross section maxima for $\mathrm{Fe}_{x} \mathrm{O}_{x}$ with $x=1,2,3$ varies roughly linearly with $x$, see Table 2, which is in line with the approximate validity of the additivity rule used earlier to estimate the EICSs of polyatomic molecules by summing up the atomic cross section [23]. However, we see also that the 
Table 3. Fit parameters using equation (5) to model the DM and BEB cross sections.

\begin{tabular}{llllllll}
\hline Method & Parameter & $\mathrm{FeO}$ & $\mathrm{FeO}_{2}$ & $\mathrm{Fe}_{2} \mathrm{O}_{2}$ & $\mathrm{Fe}_{2} \mathrm{O}_{3}$ & $\mathrm{Fe}_{3} \mathrm{O}_{3}$ & $\mathrm{Fe}_{3} \mathrm{O}_{4}$ \\
\hline \multirow{4}{*}{$\mathrm{DM}$} & $a_{1}\left(10^{-16} \mathrm{~cm}^{2} \mathrm{eV}\right)$ & 179.4 & 230.5 & 375.7 & 403.9 & 543.7 & 592.2 \\
& $a_{2}$ & 5.627 & 3.93 & 4.055 & 4.656 & 6.271 & 3.783 \\
& $a_{3}$ & -0.3345 & -0.02724 & -0.9263 & 0.09559 & -0.4229 & 0.03265 \\
& $a_{4}$ & 5.747 & -0.00994 & 1.09 & 3.905 & 6.762 & 3.032 \\
& & & & & & & \\
$\mathrm{BEB}$ & $a_{1}\left(10^{-16} \mathrm{~cm}^{2} \mathrm{eV}\right)$ & 550.7 & 647.1 & 1037 & 1275 & 1636 & 1832 \\
& $a_{2}$ & 4.106 & 4.642 & 6.139 & 3.883 & 5.647 & 3.251 \\
& $a_{3}$ & -1.415 & -1.255 & -1.614 & -1.299 & -1.502 & -1.257 \\
& $a_{4}$ & 3.284 & 2.893 & 4.233 & 2.726 & 3.899 & 2.424 \\
\hline
\end{tabular}

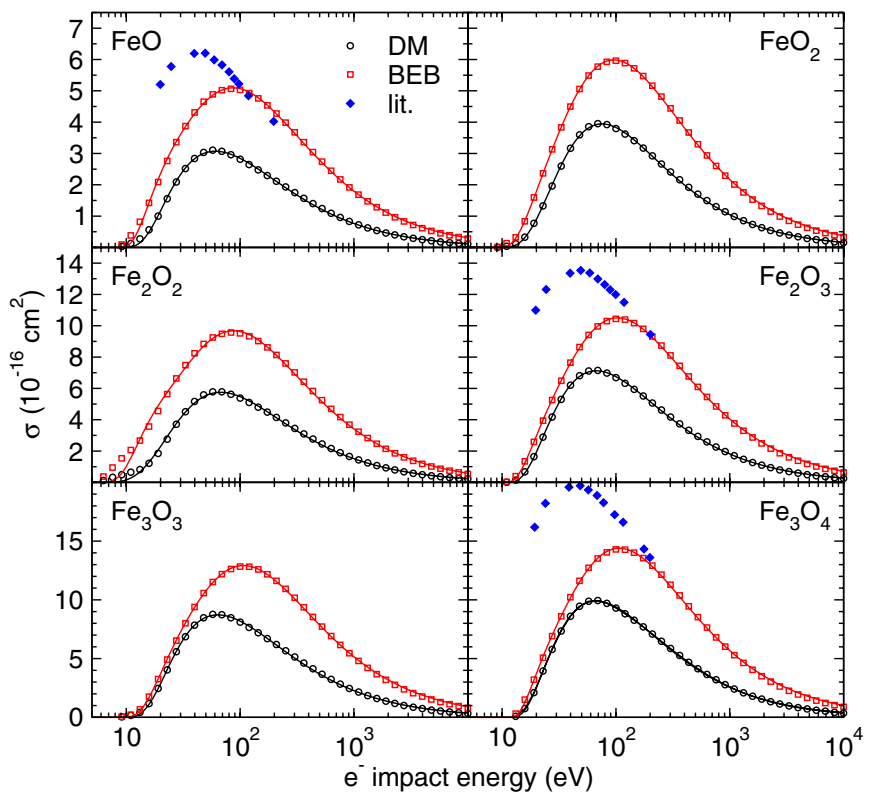

Fig. 2. DM (black circles) and BEB (red squares) EICSs obtained for the considered iron oxide molecules. The analytical fit functions obtained using equation (5) are also shown (solid lines). Estimates of the respective cross sections for $\mathrm{FeO}$, $\mathrm{Fe}_{2} \mathrm{O}_{3}$ and $\mathrm{Fe}_{3} \mathrm{O}_{4}$ obtained in reference [23] using the additivity rule are also included for comparison (blue filled diamonds).

resulting cross sections for $\mathrm{Fe}_{x} \mathrm{O}_{x}$ with $x=1,2,3$ are consistently smaller than what would be obtained by simply scaling the cross section of $\mathrm{FeO}$ with $x$. This indicates the decrease of the respective cross section due to the more compact electronic distribution upon chemical bonding as the molecules get bigger. This is also in line with the finding that the estimates for the cross sections of $\mathrm{FeO}, \mathrm{Fe}_{2} \mathrm{O}_{3}$ and $\mathrm{Fe}_{3} \mathrm{O}_{4}$ obtained from applying the additivity rule in reference [23] are larger than the DM and BEB cross sections obtained in this work, see Figure 2. We note that as early as 1997, a method has been suggested yielding a modified additivity rule to actually take into account the reduction of the molecular ionisation cross section due to molecular binding [65]. It has, however, not yet been applied to iron oxides. In the higher energy region (beyond the maxima) the BEB EICSs and the cross sections determined via the additivity rule cross each other which is
Table 4. Ratios between the cross section maxima obtained with the $\mathrm{DM}$ and $\mathrm{BEB}$ methods, i.e. $R=$ $\sigma_{\max }^{\mathrm{BEB}} / \sigma_{\max }^{\mathrm{DM}}$, and average Mulliken population, $P$, of the $\mathrm{Fe} 4 \mathrm{~s}$ orbitals in the iron oxides under consideration.

\begin{tabular}{lllll}
\hline$x$ & \multicolumn{2}{c}{$\mathrm{Fe}_{x} \mathrm{O}_{x}$} & \multicolumn{2}{c}{$\mathrm{Fe}_{x} \mathrm{O}_{x+1}$} \\
\cline { 2 - 5 } & $R$ & $P$ & $R$ & $P$ \\
\hline 1 & 1.63 & 0.56 & 1.51 & 0.42 \\
2 & 1.68 & 0.53 & 1.46 & 0.41 \\
3 & 1.46 & 0.50 & 1.44 & 0.40 \\
\hline
\end{tabular}

actually an indication that the BEB cross sections are too large at elevated energies. The DM cross sections remain lower at all energies but, in contrast to BEB, appear to be distinctly too low especially at energies far beyond the maxima since in this region the discrepancies between the three approaches should actually become smaller.

The BEB cross sections are generally significantly larger (and their maxima are shifted to higher electron impact energies) than the DM cross sections - ranging from a factor of 1.7 in case of $\mathrm{Fe}_{2} \mathrm{O}_{2}$ down to 1.4 in case of $\mathrm{Fe}_{3} \mathrm{O}_{4}$ - which is in line with a study on iron hydrogen clusters EICSs [22] in which also discrepancies between those two methods were obtained which were larger than previously assumed to be the norm. We note that there have been cases reported in which the DM method resulted in cross sections which were significantly smaller and also showed a faster decrease beyond the maximum than it was the case for cross sections obtained using other methods or experimental ones [66-68]. In reference [22] the discrepancy between DM and BEB cross sections was related to the different methodological foundations of the methods, and especially to the explicit inclusion of geometric parameters in terms of the radius of maximum radial density of atomic subshells (see also Sect. 2.1) in the DM approach. It was found that the $4 \mathrm{~s}$ electrons led to the by far most dominant contribution to the EICS of atomic Fe and as the population of this atomic orbital decreased with increasing number of hydrogen atoms in the iron hydrogen cluster, the discrepancies for the resulting EICSs between DM and BEB decreased also [22]. Hence, we also investigated how the addition of oxygen affects the population of $\mathrm{Fe} 4 \mathrm{~s}$ orbital in the considered $\mathrm{Fe}_{x} \mathrm{O}_{x}$ molecules. In Table 4, we supply the discrepancies between DM and BEB determined as the ratios between cross section maxima and the populations of the $\mathrm{Fe} 4 \mathrm{~s}$ orbital divided by the number 
of iron atoms contained in the molecule (for atomic iron this quantity would be 2). Indeed, the depopulation of the $\mathrm{Fe} 4 \mathrm{~s}$ orbital observed for the $\mathrm{Fe}_{x} \mathrm{O}_{x+1}$ molecules when compared to $\mathrm{Fe}_{x} \mathrm{O}_{x}$ correlates with the decreasing discrepancy between the methods when increasing the number of oxygen atoms in the respective molecule. The substantial depopulation of the Fe $4 \mathrm{~s}$ orbital in the oxides compared to atomic iron may underlie also the fact that the DM cross sections for $\mathrm{FeO}$ and $\mathrm{FeO}_{2}$ are smaller than the EICS of atomic iron [69], although the ionisation thresholds are not much different $(7.92 \mathrm{eV}$ for atomic iron [70], $8.53 \mathrm{eV}$ and $8.88 \mathrm{eV}$ for $\mathrm{FeO}$ and $\mathrm{FeO}_{2}$, respectively). The EICSs of $\mathrm{FeO}$ and $\mathrm{FeO}_{2}$ have maxima of $3.10 \times 10^{-16} \mathrm{~cm}^{2}$ at $59 \mathrm{eV}$ and of $3.95 \times 10^{-16} \mathrm{~cm}^{2}$ at $72 \mathrm{eV}$, respectively, while the maximum of the Fe EICS was experimentally found to be $4.08 \times 10^{-16} \mathrm{~cm}^{2}$ at $35 \mathrm{eV}$ [69]. Analogous findings have been obtained for small iron hydrogen clusters [22]. Overall, our results are in line with the interpretation given for this discrepancy in reference [22]. However, this does not explain why the discrepancies found in iron containing compounds are actually that large since discrepancies between the results of different numerical methods as well as between calculations and experiments turned out be mostly within at least $50 \%$ in the past $[13,15,44]$. In addition to the study on iron hydrogen clusters [22], an exception to this finding has also been noted for atomic tungsten yielding a discrepancy between the methods of about a factor of two [71]. This could actually be an indication that discrepancies between these two methods are enhanced by the inclusion of heavy elements in the studied compounds. Anyway, this calls also for the experimental study of EICSs of fusion-relevant compounds in order to clarify how good the DM and BEB methods work for these and which of the two methods delivers the more accurate estimates. Most fusion relevant molecular species are unusual compounds in the sense of conventional synthetic and analytical chemistry which makes the experimental investigation of them on the one hand a challenging task. On the other hand, however, this is exactly the reason why validation of the $\mathrm{DM}$ and $\mathrm{BEB}$ methods via comparison with experimental data at least for some of the molecules would be highly appreciable in order to yield an empirical measure for the utility of the methods for molecules which are difficult to investigate experimentally. In the absence of such experimental data we cannot safely judge either DM or BEB as the more accurate method, but from overall experience would rather expect experimental cross sections somewhere in between them. This argument is supported by a comparison of BEB and DM EICSs and cross sections obtained via the additivity rule [23] as in the discussion of Figure 2 with a slight favour towards BEB at least in the high energy region.

\section{Conclusion}

We calculated EICSs of iron oxide molecules, $\mathrm{Fe}_{x} \mathrm{O}_{x}$ and $\mathrm{Fe}_{x} \mathrm{O}_{x+1}$ with $x=1,2,3$, from the ionisation threshold to $10 \mathrm{keV}$ using the DM and the BEB methods using effective core potentials for the inner core electrons in the quantum chemical calculations necessary to obtain the orbital and kinetic energies required for the BEB approach. The maxima of the cross sections range from 3.10 to $9.96 \times 10^{-16} \mathrm{~cm}^{2}$ located at $59-72 \mathrm{eV}$ and 5.06 to $14.32 \times 10^{-16} \mathrm{~cm}^{2}$ located at $85-108 \mathrm{eV}$ for DM and BEB, respectively. The BEB cross sections are 1.4-1.7 times larger than the DM cross sections which could be related to the decreasing population of $\mathrm{Fe} 4 \mathrm{~s}$ orbitals upon addition of oxygen. However, experimental data on EICSs of such molecular compounds are still missing. They would be highly appreciated in order to base the assessment of the calculated cross sections on empirical foundations. We assume that results from both approaches at least give good estimates of the true cross section. Both the DM and BEB EICSs were fitted against a simple analytical expression used in modelling and simulation codes in the framework of nuclear fusion research.

This work was supported by the Austrian Ministry of Science BMWF as part of the University Infrastructure Program of the Scientific Computing Platform LFU Innsbruck. This work has been carried out within the framework of the EUROfusion Consortium and has received funding from the Euratom Research and Training Programme 2014-2018 under Grant Agreement No. 633053. The views and opinions expressed herein do not necessarily reflect those of the European Commission. Open access funding provided by University of Innsbruck.

\section{Author contribution statement}

All authors contributed equally to the paper.

Open Access This is an open access article distributed under the terms of the Creative Commons Attribution License (http://creativecommons.org/licenses/by/4.0), which permits unrestricted use, distribution, and reproduction in any medium, provided the original work is properly cited.

\section{References}

1. R.A. Pitts, S. Carpentier, F. Escourbiac, T. Hirai, V. Komarov, A.S. Kukushkin, S. Lisgo, A. Loarte, M. Merola, R. Mitteau, A.R. Raffray, M. Shimada, P.C. Stangeby, J. Nucl. Mater. 415, S957 (2011)

2. F. Tavassoli, in 6th International Conference on Creep, Fatigue and Creep-Fatigue Interaction (2013), Vol. 55, p. 300

3. M. Kytka, M. Brumovsky, M. Falcnik, J. Nucl. Mater. 409, 147 (2011)

4. R.P. Dörner, M.J. Baldwin, D. Buchenauer, G. De Temmerman, D. Nishijima, J. Nucl. Mater. 390-391, 681 (2009)

5. C. Björkas, K. Vortler, K. Nordlund, D. Nishijima, R. Doerner, New J. Phys. 11, 12 (2009)

6. G. Janeschitz, J. Nucl. Mater. 290, 1 (2001)

7. G. Federici, P. Andrew, P. Barabaschi, J. Brooks, R. Dörner, A. Geier, A. Herrmann, G. Janeschitz, K. Krieger, A. Kukushkin, A. Loarte, R. Neu, G. Saibene, M. Shimada, G. Strohmayer, M. Sugihara, J. Nucl. Mater. 313, 11 (2003) 
8. J. Roth, E. Tsitrone, A. Loarte, T. Loarer, G. Counsell, R. Neu, V. Philipps, S. Brezinsek, M. Lehnen, P. Coad, C. Grisolia, K. Schmid, K. Krieger, A. Kallenbach, B. Lipschultz, R. Doerner, R. Causey, V. Alimov, W. Shu, O. Ogorodnikova, A. Kirschner, G. Federici, A. Kukushkin, EFDA PWI Task Force, ITER PWI Team, J. Nucl. Mater. 390-391, 1 (2009)

9. R.E.H. Clark, D.H.E. Reiter, Nuclear fusion research - understanding plasma-surface interactions (Springer, Berlin, 2005)

10. A. Kendl, Int. J. Mass Spectrom. 365, 106 (2014)

11. T.D. Märk, G.H. Dunn, Electron impact ionization (Springer, Wien, 1985)

12. Y.K. Kim, M.E. Rudd, Phys. Rev. A 50, 3954 (1994)

13. Y.K. Kim, M.A. Ali, M.E. Rudd, J. Res. Natl. Inst. Stand. Technol. 102, 693 (1997)

14. H. Deutsch, T.D. Märk, Int. J. Mass Spectrom. 79, R1 (1987)

15. H. Deutsch, K. Becker, M. Probst, T.D. Märk, in Advances in atomic, molecular, and optical physics, edited by E. Arimondo, P.R. Berman, C.C. Lin (Elsevier Academic Press Inc., San Diego, 2009), Vol. 57

16. J. Colgan, S.D. Loch, M.S. Pindzola, C.P. Ballance, D.C. Griffin, Phys. Rev. A 68, 9 (2003)

17. P.L. Bartlett, A.T. Stelbovics, At. Data Nucl. Data Tables 86, 235 (2004)

18. T. Maihom, I. Sukuba, R. Janev, K. Becker, T. Märk, A. Kaiser, J. Limtrakul, J. Urban, P. Mach, M. Probst, Eur. Phys. J. D 67, 5 (2013)

19. H. Deutsch, K. Hilpert, K. Becker, M. Probst, T.D. Märk, J. Appl. Phys. 89, 1915 (2001)

20. B. Goswami, R. Naghma, B. Antony, Int. J. Mass Spectrom. 372, 8 (2014)

21. I. Sukuba, A. Kaiser, S.E. Huber, J. Urban, M. Probst, Eur. Phys. J. D 70, 11 (2016)

22. S.E. Huber, I. Sukuba, J. Urban, J. Limtrakul, M. Probst, Eur. Phys. J. D 70, 182 (2016)

23. K.L. Baluja, A. Agrawal, Phys. Lett. A 198, 225 (1995)

24. D.N. Shin, Y. Matsuda, E.R. Bernstein, J. Chem. Phys. 120, $4150(2004)$

25. D.N. Shin, Y. Matsuda, E.R. Bernstein, J. Chem. Phys. 120, 4157 (2004)

26. M. Li, S.-R. Liu, P.B. Armentrout, J. Chem. Phys. 131, 144310 (2009)

27. S. Laurent, D. Forge, M. Port, A. Roch, C. Robic, L.V. Elst, R.N. Muller, Chem. Rev. 108, 2064 (2008)

28. A. Schatz, O. Reiser, W.J. Stark, Chem. Eur. J. 16, 8950 (2010)

29. L. Machala, J. Tucek, R. Zboril, Chem. Mater. 23, 3255 (2011)

30. L. Machala, J. Tucek, R. Zboril, Chem. Mater. 23, 4271 (2011)

31. H. Shiroishi, T. Oda, I. Hamada, N. Fujima, Eur. Phys. J. D 24, 85 (2003)

32. N.O. Jones, B.V. Reddy, F. Rasouli, S. N. Khanna, Phys. Rev. B 72, 4 (2005)

33. N.O. Jones, B.V. Reddy, F. Rasouli, S.N. Khanna, Phys. Rev. B 73, 1 (2006)

34. X.L. Ding, W. Xue, Y.P. Ma, Z.C. Wang, S.G. He, J. Chem. Phys. 130, 8 (2009)

35. S. Lopez, A.H. Romero, J. Mejia-Lopez, J. Mazo-Zuluaga, J. Restrepo, Phys. Rev. B 80, 10 (2009)
36. A. Erlebach, C. Huhn, R. Jana, M. Sierka, Phys. Chem. Chem. Phys. 16, 26421 (2014)

37. M. Ju, J. Lv, X.Y. Kuang, L.P. Ding, C. Lu, J.J. Wang, Y.Y. Jin, G. Maroulis, RSC Adv. 5, 6560 (2015)

38. D. Naujoks, R. Behrisch, J.P. Coad, L. Dekock, Nucl. Fusion 33, 581 (1993)

39. A. Kirschner, V. Philipps, J. Winter, U. Kogler, Nucl. Fusion 40, 989 (2000)

40. D. Borodin, A. Kirschner, S. Carpentier-Chouchana, R.A. Pitts, S. Lisgo, C. Björkas, P.C. Stangeby, J.D. Elder, A. Galonska, D. Matveev, V. Philipps, U. Samm, Phys. Scr. T145, 7 (2011)

41. H. Deutsch, P. Scheier, K. Becker, T.D. Märk, Int. J. Mass Spectrom. 233, 13 (2004)

42. J.P. Desclaux, At. Data Nucl. Data Tables 12, 311 (1973)

43. D. Margreiter, H. Deutsch, T.D. Märk, Int. J. Mass Spectrom. Ion Process. 139, 127 (1994)

44. H. Deutsch, K. Becker, S. Matt, T.D. Märk, Int. J. Mass Spectrom. 197, 37 (2000)

45. H. Bethe, Ann. Phys. 397, 325 (1930)

46. H. Deutsch, F.X. Bronold, K. Becker, Int. J. Mass Spectrom. 365, 128 (2014)

47. R.S. Mulliken, J. Chem. Phys. 23, 1833 (1955)

48. R. Tang, J. Callaway, J. Chem. Phys. 84, 6854 (1986)

49. W.M. Huo, Y.K. Kim, Chem. Phys. Lett. 319, 576 (2000)

50. G.E. Scott, K.K. Irikura, Surf. Interface Anal. 37, 973 (2005)

51. B. Tsipinyuk, A. Bekkerman, E. Kolodney, Int. J. Mass Spectrom. 328, 2 (2012)

52. G.E. Scott, K.K. Irikura, J. Chem. Theory Comput. 1, $1153(2005)$

53. A.D. Becke, J. Chem. Phys. 98, 5648 (1993)

54. F. Weigend, R. Ahlrichs, Phys. Chem. Chem. Phys. 7, 3297 (2005)

55. F. Weigend, Phys. Chem. Chem. Phys. 8, 1057 (2006)

56. W.J. Stevens, H. Basch, M. Krauss, J. Chem. Phys. 81, 6026 (1984)

57. W.J. Stevens, M. Krauss, H. Basch, P.G. Jasien, Can. J. Chem. (Rev. Can. Chim.) 70, 612 (1992)

58. T.R. Cundari, W.J. Stevens, J. Chem. Phys. 98, 5555 (1993)

59. W. Vonniessen, J. Schirmer, L.S. Cederbaum, Comput. Phys. Rep. 1, 57 (1984)

60. M.J. Frisch, G.W. Trucks, H.B. Schlegel, G.E. Scuseria, M.A. Robb, J.R. Cheeseman, G. Scalmani, V. Barone, B. Mennucci, G.A. Petersson, H. Nakatsuji, M. Caricato, X. Li, H.P. Hratchian, A.F. Izmaylov, J. Bloino, G. Zheng, J.L. Sonnenberg, M. Hada, M. Ehara, K. Toyota, R. Fukuda, J. Hasegawa, M. Ishida, T. Nakajima, Y. Honda, O. Kitao, H. Nakai, T. Vreven, J.A. Montgomery Jr., J.E. Peralta, F. Ogliaro, M.J. Bearpark, J. Heyd, E.N. Brothers, K.N. Kudin, V.N. Staroverov, R. Kobayashi, J. Normand, K. Raghavachari, A.P. Rendell, J.C. Burant, S.S. Iyengar, J. Tomasi, M. Cossi, N. Rega, N.J. Millam, M. Klene, J.E. Knox, J.B. Cross, V. Bakken, C. Adamo, J. Jaramillo, R. Gomperts, R.E. Stratmann, O. Yazyev, A.J. Austin, R. Cammi, C. Pomelli, J.W. Ochterski, R.L. Martin, K. Morokuma, V.G. Zakrzewski, G.A. Voth, P. Salvador, J.J. Dannenberg, S. Dapprich, A.D. Daniels, Ö. Farkas, J.B. Foresman, J.V. Ortiz, J. Cioslowski, D.J. Fox, Gaussian 09, Revision D.01 (Gaussian, Inc., Wallingford, CT, 2009)

61. A.T. Garcia-Sosa, M. Castro, Int. J. Quantum Chem. 80, 307 (2000) 
62. K.P. Huber, G. Herzberg, Molecular spectra and molecular structure. IV. Constants of diatomic molecules (Van Nostrand Reinhold, New York, 1979)

63. R.B. Metz, C. Nicolas, M. Ahmed, S.R. Leone, J. Chem. Phys. 123, 114313 (2005)

64. D.L. Hildenbrand, Chem. Phys. Lett. 34, 352 (1975)

65. H. Deutsch, K. Becker, T.D. Märk, Int. J. Mass Spectrom. 167, 503 (1997)

66. B.K. Antony, K.N. Joshipura, N.J. Mason, J. Phys. B: At. Mol. Opt. Phys. 38, 189 (2005)
67. H.N. Kothari, S.H. Pandya, K.N. Joshipura, J. Phys. B: At. Mol. Opt. Phys. 44, 7 (2011)

68. P. Modak, J. Kaur, B. Antony, Phys. Plasmas 24, 083514 (2017)

69. M.B. Shah, P. McCallion, K. Okuno, H.B. Gilbody, J. Phys. B: At. Mol. Opt. Phys. 26, 2393 (1993)

70. D.H. Russell, T. Solouki, J.V.B. Oriedo, J. Am. Soc. Mass Spectrom. 6, 543 (1995)

71. H. Deutsch, K. Becker, T.D. Märk, Int. J. Mass Spectrom. 271, 58 (2008) 